\title{
To study the effect of maternal basal metabolic index on the pregnancy and perinatal outcome
}

\author{
Rekha Wadhwani, Sangita Khobragade*, Pallavi Singh
}

Department of Obstetrics and Gynecology, Sultania Zanana hospital, GMC, Bhopal, India

Received: 22 April 2016

Accepted: 16 May 2016

\section{*Correspondence:}

Dr. Sangita Khobragade,

E-mail: sangitakhobragade5@gmail.com

Copyright: (c) the author(s), publisher and licensee Medip Academy. This is an open-access article distributed under the terms of the Creative Commons Attribution Non-Commercial License, which permits unrestricted non-commercial use, distribution, and reproduction in any medium, provided the original work is properly cited.

\begin{abstract}
Background: Obesity and underweight is a leading, preventable cause of mortality worldwide and it is one of the most serious public health problems of the 21 st century. In developing countries like India, the obesity and underweight are very important risk factors for maternal and neonatal mortality and morbidity. The objective of the study was to evaluate the effect of maternal BMI on the pregnancy outcome and perinatal outcome.

Methods: our study included 504 antenatal cases attending OPD in Sultania Zanana hospital, Bhopal, India in their first trimester in their first visit, from the period of July2014 to June 2015. BMI of the cases calculated and categorized the women in five groups as per WHO and National Institute of Health guidelines1-2 and they were followed up in their subsequent visits in relation to any pregnancy complication and perinatal outcome.

Results: It was observed that majority of women $402(79.7 \%)$ were between the age group of 20-25 years. Mean Age - 23.33 yrs. maximum number of women i.e. 242 (48 \%) were in Normal weight group with BMI between 18.5- 24.9. Obesity is associated with increased incidence of pre-eclampsia, gestational hypertension, gestational diabetes, induced delivery, Instrument/assisted deliveries, caesarean delivery, ICU admissions complicating maternal outcome and LGA, NICU admissions and perinatal mortality complicating perinatal outcome; while underweight women appear to have Anemia, IUGR, post-partum infections and SGA babies.

Conclusions: From this tudy, we concluded that the health of women throughout their child bearing years should be addressed, to improve the pregnancy and the perinatal outcomes. Therefore, education programs, health services and nutrition consultation are recommended for women in reproductive age.
\end{abstract}

Keywords: BMI, Obesity, Pre-eclampsia

\section{INTRODUCTION}

Pregnancy is an important phase of nutrient requirement as the nutritional demands of pregnancy are extraordinary, nutritional status of a women in her pregnancy is the main modifiable factor influencing pregnancy and perinatal outcome. ${ }^{1-3} \mathrm{BMI}$, body mass index is an important predictor of nutritional status of pregnant woman, which has been considered as an important prognostic indicator of pregnancy outcomes. BMI, body mass index, or quetelet index is a value derived from the weight and height of an individual. The $\mathrm{BMI}$ is defined as the body mass divided by the square of the body height, and is universally expressed in units of $\mathrm{kg} / \mathrm{m}^{2}$, resulting from mass in kilogram and height in meters. The BMI is an attempt to quantify the nutritional status of an individual, and then categorize that person as underweight, normal weight, overweight, or obese based on that value. ${ }^{4,5}$

During the last two decades, there has been an alarming rise in the incidence of obesity all over the world. India is now facing a double burden of this disease with undernutrition and underweight on one side, and a rapid upsurge in obesity and overweight, particularly in the urban settings on the other side. Both lean and obese women carry a risk for adverse pregnancy outcomes. ${ }^{6}$ 
The aim of this study is to assess the effect of maternal $\mathrm{BMI}$ on pregnancy outcome and perinatal outcome.

\section{METHODS}

The present study titled the effect of maternal body mass index on pregnancy outcome and perinatal outcome is a prospective hospital based study conducted from July 2014 to June 2015 in department of obstetrics and gynaecology, Sultania Zanana hospital, Bhopal, India. 504 Antenatal women attending OPD in Sultania Zanana hospital randomly selected for the study in their first trimester in their first visit fulfilling inclusion criteria. Their consent for the study was obtained. Then they were allocated for the study. Inclusion criteria were Antenatal women in their first visit in their first trimester of pregnancy, singleton pregnancy Exclusion criteria were Antenatal women in second trimester and third trimester of pregnancy, multiple pregnancy, and medical disorders like chronic hypertension, hypothyroidism, and diabetes mellitus.

The women were categorized into five groups according to their BMI as follows (on the basis of the WHO and the National Institute of Health guidelines):

1. Underweight (group I): Less than or equal to BMI $18.50 \mathrm{~kg} / \mathrm{m}^{2}$.

2. Normal (group II): BMI $18.50-24.9 \mathrm{~kg} / \mathrm{m}^{2}$.

3. Overweight (group III): BMI $25-29.9 \mathrm{~kg} / \mathrm{m}^{2}$.

4. Obese (group IV): BMI $30-34.9 \mathrm{~kg} / \mathrm{m}^{2}$.

5. Morbidly Obese (group V): BMI greater than 35 $\mathrm{kg} / \mathrm{m}^{2}$.
The group with normal BMI $\left(18.50-24.9 \mathrm{~kg} / \mathrm{m}^{2}\right)$ was used as reference group for the analysis. Women were followed in their subsequent visits in relation to any complication developed during pregnancy. Perinatal outcome was also observed.

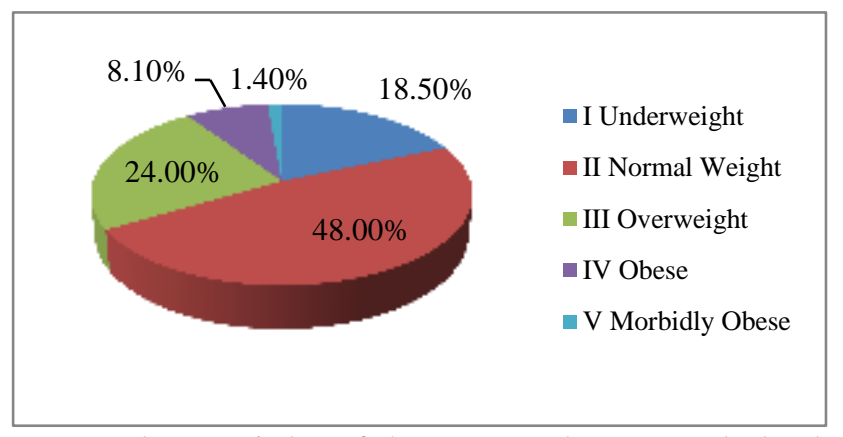

BMI: Body mass index of these antenatal women calculated using formula: $\mathrm{BMI}=$ weight $\mathrm{kg} /$ height $\mathrm{m}^{2}$.

\section{Figure 1: Distribution of women according to BMI.}

\section{RESULTS}

The study included 504 antenatal women in their first trimester attending OPD in Sultania Zanana Hospital, Bhopal, India from the period of July 2014 to 2015. It was observed that majority of women 402 (79.7\%) were between the age group of 20-25 years. Mean Age $=23.33$ years. The maximum number of women i.e. $212(42.1 \%)$ have studied up to high school followed by $30 \%$ women who were either illiterate or have basic education till primary school. Majority of women 207 (41.1\%) belongs to lower middle class. it is observed that maximum number of women i.e. 242 (48 \%) were in normal weight group with BMI ranges between 18.5 and 24.9 .

Table 1: Comparison between BMI and pregnancy outcome.

\begin{tabular}{|c|c|c|c|c|c|c|}
\hline Characteristics & $\begin{array}{l}\text { I Underweight } \\
(\mathbf{n}=93)\end{array}$ & $\begin{array}{l}\text { II Normal } \\
(\mathrm{n}=\mathbf{2 4 2})\end{array}$ & $\begin{array}{l}\text { III Overweight } \\
(n=121)\end{array}$ & $\begin{array}{l}\text { IV Obese } \\
(n=41)\end{array}$ & $\begin{array}{l}\text { V Morbidly } \\
\text { Obese }(n=7)\end{array}$ & P-value \\
\hline Pre- eclampsia & $5(5.37)$ & $15(6.19)$ & $14(11.57)$ & 07 ( 17.07) & $03(42.85)$ & 0.001 \\
\hline Gestational hypertension & $11(11.82)$ & $32(13.22)$ & $33(27.27)$ & $14(34.14)$ & $04(57.14)$ & $<0.001$ \\
\hline Abruptio placentae & $01(1.07)$ & $03(1.23)$ & $02(1.65)$ & $02(4.87)$ & $01(14.28)$ & $0.091 *$ \\
\hline Placenta previa & $01(1.07)$ & $01(0.41)$ & $02(1.65)$ & $01(2.43)$ & $0(0)$ & $0.336 *$ \\
\hline Anemia & $34(36.5)$ & $41(16.94)$ & $20(16.52)$ & $05(12.19)$ & $01(14.28)$ & 0.001 \\
\hline IUGR & $13(13.97)$ & $08(3.30)$ & $04(3.30)$ & $02(4.87)$ & $0(0)$ & 0.003 \\
\hline Gestational diabetes & $0(0)$ & $01(0.41)$ & $02(1.65)$ & $04(9.75)$ & $02(28.57)$ & $<0.001 *$ \\
\hline Preterm labour & $12(12.9)$ & $15(6.19)$ & $09(7.43)$ & $05(12.19)$ & $01(14.28)$ & 0.264 \\
\hline Abortion & $10(10.75)$ & $03(1.23)$ & $03(2.47)$ & $06(14.63)$ & $02(28.57)$ & $<0.001 *$ \\
\hline $\begin{array}{l}\text { Need for induction of } \\
\text { labour }\end{array}$ & $08(8.60)$ & $16(6.61)$ & $10(8.26)$ & $13(34.14)$ & $03(42.8)$ & $<0.001$ \\
\hline
\end{tabular}

* Fisher Exact test. p value $<0.05$ ( Significant) p value $<0.001$ ( highly significant )Figures in parenthesis indicates percentage

As observed in Table 1 that highest percentage of preeclampsia $(42.85 \%)$ was seen in women in category of morbidly obese (V) BMI and was found to statistically significant $(\mathrm{p}=0.001)$. It is also seen that BMI and preeclampsia shows linear trend. As BMI decreases the percentage of pre-eclampsia also decreases. When BMI was compared with gestational hypertension $(n=94)$ it is found that as BMI increases, the percentage of gestational hypertension also increases. Amongst 7 morbidly obese women, 4 presented with gestational hypertension 
(57.14\%) and is found to be statistically highly significant $(p<0.001)$. Out of 93 women's from BMI underweight (I) category 34 women presented with anemia $(36.5 \%)$ and is found to be statistically significant $(\mathrm{p}=0.001)$. Amongst 93 Underweight women 13 (13.97\%) presented with IUGR as maternal outcome and found to be statistically significant $(\mathrm{p}=0.003)$. Percentage of gestational diabetes was highly seen in morbidly obese patients $(28.57 \%)$ and is found to be highly significant ( $\mathrm{p}<0.001)$ maternal outcome as abortion is mostly seen amongst morbidly obese patients $(28.57 \%)$ and is found to be highly statistically significant with $\mathrm{p}<0.001$. Patients who needed induction of labour were highly seen amongst morbidly obese $(42.8 \%)$ and obese women $(34.14 \%)$ and found to be highly significant $(\mathrm{p}<0.001)$.

Table 2: Comparison between BMI and pregnancy outcome (post-partum).

\begin{tabular}{|c|c|c|c|c|c|c|}
\hline $\begin{array}{l}\text { Pregnancy outcome } \\
\text { (post partum) }\end{array}$ & $\begin{array}{l}\text { I Underweight } \\
(\mathrm{n}=93)\end{array}$ & $\begin{array}{l}\text { II Normal } \\
(\mathrm{n}=\mathbf{2 4 2})\end{array}$ & $\begin{array}{l}\text { III Overweight } \\
(n=121)\end{array}$ & $\begin{array}{l}\text { IV Obese } \\
(n=41)\end{array}$ & $\begin{array}{l}\text { V Morbidly } \\
\text { obese } \\
(n=7)\end{array}$ & P-value \\
\hline PPH & $07(7.52)$ & $14(5.78)$ & $07(5.78)$ & $06(14.63)$ & $02(28.57)$ & 0.068 \\
\hline Infections & $14(15.05)$ & $15(6.19)$ & $09(7.43)$ & 05 ( 12.19) & $01(14.28)$ & 0.101 \\
\hline ICU admission & $07(7.52)$ & $10(4.13)$ & $08(6.61)$ & $10(24.39)$ & $03(42.85)$ & $<0.001$ \\
\hline
\end{tabular}

p value $<0.05$ ( Significant);p value $<0.001$ ( highly significant );Figures in parenthesis indicates percentage

Table. 2 shows pregnancy outcome during post-partum period, the most common complication was found to be Infection which included either wound sepsis or infection post LSCS seen in 44 women $(8.73 \%)$. It is observed that PPH (post-partum heamorrhage) is mostly seen amongst morbidly obese category $(28.57 \%)$ followed by obese $(14.63 \%)$. While infections (either LSCS wound /episiotomy or other) is mostly seen in underweight category $(15.05 \%)$ and morbidly obese category (14.28 $\%)$.In distribution of patients who were admitted in ICU in post-partum periods with BMI it was seen that $42.85 \%$ of morbidly patients needed admission followed by $24.39 \%$ in obese category. Comparison of BMI with ICU admission shows highly significant value $(\mathrm{p}<0.001)$.

Table 3. Comparison between BMI and Mode of delivery

\begin{tabular}{|llllll|}
\hline Mode of delivery & $\begin{array}{l}\text { I Underweight } \\
(\mathbf{n = 9 3})\end{array}$ & $\begin{array}{l}\text { II Normal } \\
(\mathbf{n = 2 4 2})\end{array}$ & $\begin{array}{l}\text { III Overweight } \\
(\mathbf{n = 1 2 1})\end{array}$ & $\begin{array}{l}\text { IV Obese } \\
(\mathbf{n = 4 1 )}\end{array}$ & $\begin{array}{l}\text { V Morbidly obese } \\
(\mathbf{n}=7)\end{array}$ \\
\hline Vaginal & $58(62.36)$ & $145(59.91)$ & $58(47.93)$ & $20(48.78)$ & $01(14.28)$ \\
\hline LSCS ( Total ) & $18(19.35)$ & $62(25.61)$ & $33(27.27)$ & $13(34.14)$ & $04(57.14)$ \\
\hline Instrumental/ Assisted & $17(18.27)$ & $35(14.46)$ & $30(24.79)$ & $08(19.51)$ & $02(28.57)$ \\
\hline
\end{tabular}

Figures in parenthesis indicates percentage.

As observed in Table. 3, out of total LSCS (either emergency or elective) highest percentage was seen in morbidly obese patients (57.14\%). Comparison of LSCS and BMI shows linear trend of increasing. As BMI increases, the prevalence of LSCS also increases. Out of total 92 assisted/instrumental deliveries, maximum was seen in morbidly obese category of BMI $(28.57 \%)$.

Table 4. Comparison of BMI and perinatal outcome.

\begin{tabular}{|c|c|c|c|c|c|c|}
\hline Perinatal outcome & $\begin{array}{l}\text { I Underweight } \\
(\mathbf{n}=93)\end{array}$ & $\begin{array}{l}\text { II Normal } \\
(n=242)\end{array}$ & $\begin{array}{l}\text { III Overweight } \\
(\mathbf{n}=\mathbf{1 2 1})\end{array}$ & $\begin{array}{l}\text { IV Obese } \\
(n=41)\end{array}$ & $\begin{array}{l}\text { V Morbidly } \\
\text { obese } \\
(\mathrm{n}=7)\end{array}$ & P-value \\
\hline SGA & $18(19.35)$ & $09(3.71)$ & $04(3.30)$ & $03(7.31)$ & $0(0)$ & $<0.001$ \\
\hline LGA & $0(0)$ & $03(1.23)$ & $08(6.61)$ & $06(14.63)$ & $02(28.57)$ & $<0.001 *$ \\
\hline Preterm & $12(12.9)$ & $15(6.19)$ & $09(7.43)$ & $05(12.19)$ & $01(14.28)$ & 0.264 \\
\hline NICU admission & $07(7.52)$ & $10(4.13)$ & $09(7.43)$ & $07(17.07)$ & $03(42.85)$ & 0.026 \\
\hline Perinatal Mortality & $04(4.3)$ & $02(0.82)$ & $02(1.65)$ & $02(4.87)$ & $01(14.28)$ & $0.024 *$ \\
\hline
\end{tabular}

p value $<0.05$ ( Significant); p value $<0.001$ ( highly significant ); $*$ Fisher Exact test; Figures in parenthesis indicates percentage

As observed in Table.4 which shows comparison of BMI and perinatal outcome, It is seen that SGA babies in Underweight group was highest 18 (19.35\%) and statistically highly significant ( $\mathrm{p}<0.001)$ LGA was found in morbidly obese category (28.57\%), followed by 14.63
$\%$ in obese, $6.61 \%$ in overweight. LGA shows linear decreasing trend with BMI and is highly significant ( $p<0.001$ ). As BMI decreases, percentage of LGA babies decreases. In comparing BMI with preterm birth, maximum cases found (14.28\%) in morbidly obese group 


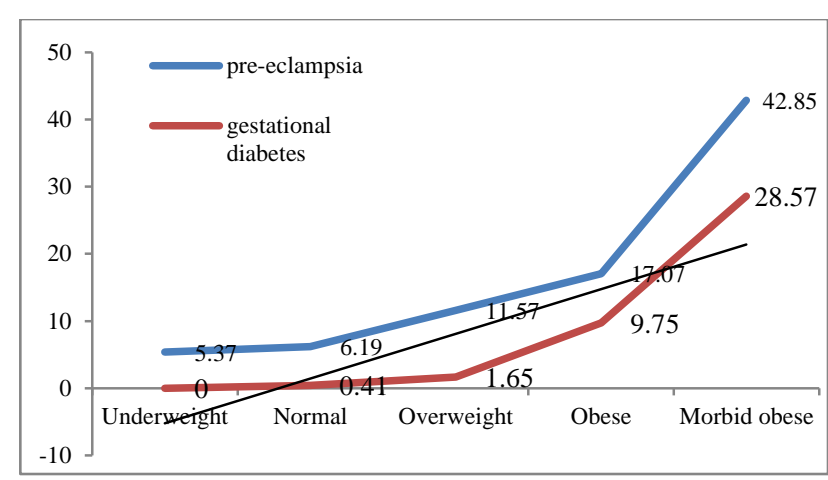

Figure 2: Linear trend of BMI with maternal outcome (pre-eclampsia and gestational diabetes).

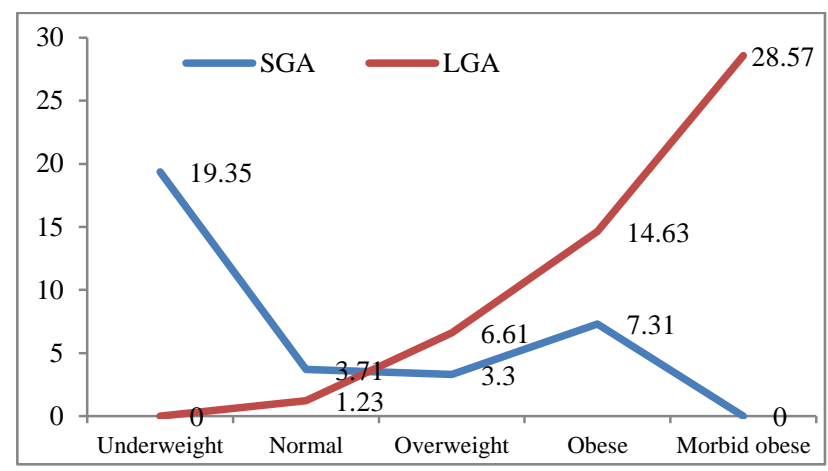

Figure.3 Trend of BMI with foetal outcome ( SGA and LGA ).

The percentage of NICU (Neonatal intensive care unit) admission is highest (42.85\%) amongst BMI with morbid obesity and is found to be statistically significant. $(\mathrm{p}=0.026)$. Out of total, 11 perinatal mortality, highest percentage $(14.28 \%)$ was seen in morbidly obese group. The comparison of BMI along with perinatal mortality was found to be significant $(\mathrm{p}=0.024)$.

\section{DISCUSSION}

Under nutrition and obesity continues to be a risk factor for maternal and neonatal morbidity and mortality .This study adds to the increasing body of evidence which suggests that obesity, measured by BMI, predisposes women to complicated pregnancies and increased obstetric interventions. We found a linear relationship between increasing body mass index and the risk of developing pre-eclampsia, gestational hypertension, gestational diabetes. While reduced body mass index shows relationship with Small for gestational age.

Major determinants of the maternal and fetal outcome in this study are BMI classification at the time of admission.

In present study the percentage of underweight women were $18.5 \%$ compared with other major studies it was $15.9 \%$ (Aimukhametova $\mathrm{G}$ et al.) and $14.79 \%$ (Verma A and Shrimali L). ${ }^{8,10}$ In a study by Demont-Heinrich $\mathrm{C}$ et al $2 \%$ belonged to morbidly obese while in present study the it was $1.4 \% .{ }^{11}$ Percentage of obese women in present study is 8.1 while in study carried by Aimukhametova G et al and Verma A and Shrimali L, it is 10.8 and 10.3 respectively. ${ }^{8,10}$.

Table 5: BMI comparison in different studies.

\begin{tabular}{|llllll|}
\hline BMI Study & $\begin{array}{l}\text { Underweight } \\
(\%)\end{array}$ & $\begin{array}{l}\text { Normal weight } \\
(\%)\end{array}$ & $\begin{array}{l}\text { Overweight } \\
(\%)\end{array}$ & $\begin{array}{l}\text { Obese } \\
(\%)\end{array}$ & $\begin{array}{l}\text { Morbidly obese } \\
(\%)\end{array}$ \\
\hline Present study & 18.5 & 48 & 24 & 8.1 & 1.4 \\
\hline Sohinee Bhattacharya et al & 11.7 & 58.1 & 21.9 & 7.7 & 0.6 \\
\hline AnjanaVerma and Lalit Shrimali $^{8}$ & 14.79 & 51.78 & 21.04 & 10.33 & 1.65 \\
\hline ShahlaYazdani et al $^{9}$ & 12.8 & 41.2 & 35.6 & 9.8 & 0.6 \\
\hline GulzhanAimukhametovaet al. $^{10}$ & 15.9 & 64.3 & 8.9 & 10.8 & 0 \\
\hline Christine Demont-Heinrich $^{11}$ & 5.2 & 57.8 & 23.0 & 12 & 2 \\
\hline HamidehPakniat et al $^{12}$ & 6.3 & 49.4 & 30.7 & 13.6 & - \\
\hline
\end{tabular}

In present study pre eclampsia as maternal outcome was majorly seen in morbidly obese $(42.85 \%)$ with p-value of 0.001 . In another study carried out by Dasgupta A et al showed $55.5 \%$ of pre eclampsia in morbidly obese. ${ }^{14}$ Also a study by Bhattacharya $\mathrm{S}$ et al it was found to be $28.2 \%$ with $\mathrm{p}$ value $<0.05$. $^{7}$ In obese the percentage in present study was $17.07 \%$ compare with $14.7 \%$ and $12.2 \%$ (Bhattacharya $\mathrm{S}$ et al and Yazdani $\mathrm{S}$ et al respectively). ${ }^{7,9}$ In present study as well as other studies above, preeclampsia was found to be statistically significant with women with raised body mass index.
Present study shows increase in percentage of gestational hypertension with increase in BMI (p-value 0.001) Maximum was seen in $57.14 \%$ in morbidly obese compared with study by Dasgupta et al (71.4\%). ${ }^{14}$ Other studies by Bhattacharya $\mathrm{S}$ et al and Verma $\mathrm{A}$ et al the percentage was 42.2 and 30.7 respectively with $p$ value $<0.05$ and $0.01 .^{7,8}$ Gestational hypertension in underweight in present study was found to $11.8 \%$ while in study by Bhattacharya $\mathrm{S}$ et al it was $13.6 \%$ and least $1.8 \%$ in study by Demont Heinrich $\mathrm{C}$ et al. ${ }^{7,11}$ 
In present study induced labour as maternal outcome was mostly seen in morbidly obese category (42.8\%) with p-value $<0.001$ which is highly significant. When we compare present study with other studies, the percentage of induced labour in almost every study in morbidly obese was high with p-value statistically significant. Dasgupta et al found $64.2 \%$ induced labour in morbidly obese, while ShahlaY et al, Sohinee B et al, Heinrich CD showed $50 \%, 49 \%$ and $41.4 \%$ respectively. ${ }^{11}$

Gestational diabetes in present study was seen in morbidly obese with $28.57 \%$ and found to be statistically significant $(p<0.001)$. Similar studies showed the percentage of 23 ( $\mathrm{p}<0.001)$ and $7.5(\mathrm{p}<0.05)$ by Verma $A$ et al and Heinrich $C D$ et al. ${ }^{8,11}$ In underweight no prevalence of gestational diabetes was seen. While studies carried by Heinrich CD et al. and Pakniat Het al showed $1.4 \%$ and $1.1 \% .^{12}$

Present study shows no significance of preterm labour and BMI with maximum percentage is seen in morbidly obese group $(14.28 \%)$ followed by underweight (12.9 $\%$ ). Other studies by Bhattacharya S et al , P. Kalk et al and Heinrich et al shows statistical significance. ${ }^{7,13,11}$

In present study abruptio placentae was mostly seen in morbidly obese group (14.28\%). In study by Bhattacharya $\mathrm{S}$ et al it shows $1.9 \%{ }^{13}$ Also in present study the prevalence of placenta previa is predominantly seen in obese group $(2.43 \%)$, while in studies done by Bhattacharya et al it showed $0.2 \% .^{13}$

In present study anemia and IUGR as maternal outcome was seen mostly in underweight BMI group, $36.5 \%$ and $13.97 \%$ respectively $(\mathrm{p}=0.001$ and $\mathrm{p}=0.003)$. In studies done by Verma A et al. the prevalence of anemia and IUGR was $58.6 \%$ and $17.2 \%$. $(\mathrm{p}<0.001$ and $\mathrm{p}=0.003) .{ }^{8}$ In another study by Dasgupta et al showed $21.1 \%$ women with IUGR from morbidly obese BMI compared to none in present study. ${ }^{14}$

In present study abortions is majorly seen in morbidly obese group with $28.57 \%$ ( $p<0.001$ ) while in another study by Dasgupta et al shows no women in morbidly obese group with abortion. ${ }^{14}$

In present study, women underwent LSCS were more in morbidly obese $57.14 \%$ followed by obese in $34.14 \%$. Study by Bhattacharya et al it is seen in $42.7 \%$ and 30.8 $\%$ in morbidly obese and obese. ${ }^{7}$ Other studies by Yazdani et al, Verma A et al, Heinrich et al and Dasgupta et al in morbidly obese who underwent LSCS were $7.6 \%$, $69.2 \%, 51.4 \%$ and $68.7 \%$ respectively. ${ }^{7-11}$ Thus most of studies showed relationship between raised BMI and LSCS also instrumental/assisted delivery in present study was most seen in morbidly obese $(28.57 \%)$, while in study by Bhattacharya et al it is seen in $24.2 \%{ }^{7}$ Other studies by Verma $\mathrm{A}$ et al showed no women required assisted/instrumental delivery in morbidly obese BMI group, while in a study by Dasgupta et al it was seen in $37.5 \%$. $^{8,14}$

In present study, post-partum period, $\mathrm{PPH}$ were seen in morbidly obese $(28.57 \%)$, while infection in underweight (15.05\%) and morbidly obese (14.28\%). A similar study by Verma A showed no women with PPH in morbidly obese group. ${ }^{8}$ A study by Dasgupta A et al showed $31.6 \%$ PPH in morbidly obese group. ${ }^{14}$ A study by Yazdani S et al showed no infection in underweight group while in morbidly obese it was found to be $4 \%$ compared to 14.28 in present study, while study by Verma A et al infection in underweight as $14.2 \%$ and $22.2 \%$ in morbidly obese. In a study by Dasgupta $A$ et al the prevalence of infection in morbidly obese was seen in $15.8 \%$. $^{9,7,14}$

In present study, SGA (small for gestational age) as perinatal outcome was seen mostly in underweight category of BMI with $\mathrm{p}$ value $<0.001$ and was highly significant. Similar study by Verma A also showed the prevalence of $18.9 \%$ in underweight with $p<0.001$, however it also showed $7.69 \%$ of SGA in morbidly obese while in present study there were no SGA found in this BMI group. Another study carried out by Heinrich $\mathrm{C}$ et al showed SGA in underweight BMI as $18.6 \%$ and in morbidly obese as $10.5 \% .^{11}$

In present study, large for gestational age (LGA) was seen predominantly in morbidly obese $(28.57 \%)$ with pvalue $<0.001$ and was statistically significant. Similar studies carried out by Verma A et al Demont-Heinrich C et al showed that LGA in morbidly obese BMI was seen in $23 \%$ and $14 \%$ respectively with statistical significance. ${ }^{8,11}$ Present study shows no LGA as perinatal outcome in underweight while another study by Kalk P et al showed 7.8\% LGA in underweight BMI category.

\section{CONCLUSION}

In present study, both the extremes of the maternal BMI showed a strong association with the pregnancy complications and the perinatal outcomes.

Maternal BMI shows strong associations with pregnancy complications and outcomes. Obesity is associated with increased incidence of pre-eclampsia, gestational hypertension, gestational diabetes, induced delivery, Instrument/assisted deliveries, caesarean delivery, ICU admissions complicating maternal outcome and LGA, NICU admissions and perinatal mortality complicating perinatal outcome; while underweight women appear to have anemia, IUGR, post-partum infections and SGA babies.

Therefore, we advise pregnant woman to gain a normal BMI before and during pregnancy, with advice of their dietician and doctor prior to getting pregnant.

To conclude, the health of women throughout their child bearing years should be addressed, to improve the 
pregnancy and the perinatal outcomes. Therefore, education programs, health services and nutrition consultation are recommended for women in reproductive age.

Funding: No funding sources

Conflict of interest: None declared

Ethical approval: The study was approved by the Institutional Ethics Committee

\section{REFERENCES}

1. BMI Classification. Global Database on Body Mass Index. World Health Organization. 2006.

2. Classification of overweight and obesity. National institute of health October. 2000.

3. Institute of Medicine. Nutrition during pregnancy. Washington: National Academy of Sciences; 1990.

4. Garrow JS, Webster J. Quetelet's index (W/H2) as a measure of fatness. Int J Obes. 1985;9(2):147-53.

5. Eknoyan G, Quetelet A (1796-1874) - the average man and indices of obesity. Nephrol Dial Transplant. 2008;23(1):47-51.

6. National Family Health Survey (NFHS-3) India 2005-2006.

7. Bhattachary S, Campbell DM, Liston WA. Effect of body mass index on pregnancy outcomes in nulliparous women delivering singleton babies. BMC Public Health. 2007;7:168.
8. Verma A, Shrimali L. Index maternal body mass and pregnancy outcome. J Clindiagn Res. 2012;6(9):1531-3.

9. Yazdani S, Yosofniyapasha Y, Nasab BH, Mojaveri $\mathrm{MH}$, Bouzari Z. Effect of maternal body mass index on pregnancy outcome and newborn weight. 2012;5:34.

10. Aimukhametova G, Ukybasova T, Hamidullina Z, Zhubanysheva K, Harun-Or-Rashid M, Yoshida Y, Kasuya H. The impact of maternal obesity on mother and neonatal health: study in a tertiary hospital of Astana, Kazakhstan. Nagoya J Med Sci. 2012;74(12):83-92.

11. Demont-Heinrich C. The association of prepregnancy body mass index and adverse maternal and perinatal outcomes; colorado department of public health and environment. 2009;69:1-5.

12. Pakniat H, Movahed F. Association between body mass index and weight gain during pregnancy with preterm delivery. Journal of Qazvin University of Medical Sciences. 2013;17(3):12-9.

13. Kalk P, Guthmann F. Impact of maternal body mass index on neonatal outcome. Eur $\mathrm{J}$ Med Res. 2009; 14(5):216-22.

14. Dasgupta A, Habeebullah S. Pregnancy outcome among Obese Indians - a prospective cohort study in a tertiary care centre in south India. Int J Sci Stud. 2014;2(2):13-18.

Cite this article as: Wadhwani $\mathrm{R}$, Khobragade $\mathrm{S}$, Singh P. To study the effect of maternal basal metabolic index on the pregnancy and perinatal outcome. Int J Reprod Contracept Obstet Gynecol 2016;5:1953-8. 